\title{
Implementing a national strategy for patient safety: lessons from the National Health Service in England
}

\author{
R Q Lewis, M Fletcher
}

Qual Saf Health Care 2005;14:135-139. doi: 10.1136/qshc.2004.011882

Improving patient safety has become a core issue for many modern healthcare systems. However, knowledge of the best ways for government initiated efforts to improve patient safety is still evolving, although there is considerable commonality in the challenges faced by countries. Actions to improve patient safety must operate at multiple levels of the healthcare system simultaneously. Using the example of the NHS in England, this article highlights the importance of a strategic analysis of the policy process and the prevailing policy context in the design of the national patient safety strategy. The paper identifies a range of policy "levers" (forces for change) that can be used to support the implementation of the national safety initiative and, in particular, discusses the strengths and limitations of the "business case" approach that has attracted recent interest. The paper offers insights into the implementation of national patient safety goals that should provide learning for other countries.

See end of article for authors' affiliations

Correspondence to:

Dr R Q Lewis, National

Patient Safety Agency, 4-8 Maple Street, London WIT 5HD, UK; richard.lewis@ npsa.nhs.uk

Accepted for publication 30 August 2004
A ll healthcare systems around the world occasionally unintentionally harm patients whom they are seeking to help. In recognition of this, patient safety has become a fundamental part of the drive to improve quality in the National Health Service (NHS) in England. This has been given impetus by findings which highlight a current failure to learn systematically from things that go wrong, in marked contrast to other high risk industries. ${ }^{1}$ Completely safe health care is an ideal which may never be realised. Nonetheless, it expands our view of what might be possible. ${ }^{2}$ The creation of healthcare systems that systematically and continuously reflect, learn, and act to reduce unintended patient harm may be a more achievable aim.

There is a growing interest in many countries in the role and impact of government initiated strategies to improve patient safety. ${ }^{3}$ This paper describes the evolving approach of the National Patient Safety Agency (NPSA) to the implementation of a system-wide strategy for safer health care in England (box 1). It considers how such a strategy must be located within a clear conceptual framework of policy making and take account of the prevailing policy context if it is to be effective. A range of "levers for change" is identified to support implementation of patient also considered. safety goals. Implications for other countries are

\section{ESTABLISHING A PATIENT SAFETY AGENDA}

There are marked differences in how health care is organised and financed in countries across the world. However, there are a number of common interrelated challenges which strategies to improve the safety of patient care must address, particularly where governments seek to initiate reforms. ${ }^{2}$

The first challenge is to create an environment receptive to change at all levels of the healthcare system. This requires a will to improve patient safety among key players such as doctors, nurses, managers, allied health professionals, and policy makers. In a number of countries, landmark reports from respected health institutions have helped galvanise this will to act and establish an agenda for action. ${ }^{15}$ This has been accompanied by a call for strong patient safety leadership at all levels of the health system. ${ }^{\circ}$

Building a will for change also requires effective measurement. There is a need to understand better the nature and scale of harm to patients resulting from current systems of care. This is also essential for setting priorities for action. ${ }^{7}$ In a number of countries this knowledge has been generated through research studies involving retrospective review of patient health care records. ${ }^{8-11}$ Large scale incident reporting systems have been developed internationally such as the National Reporting and Learning System in England and Wales and the Australian Incident Monitoring System in Australia. ${ }^{12}$

A further challenge is to ensure that measurement goes beyond simply counting the frequency of patient safety incidents and incorporates an understanding of the factors that contribute to safety shortcomings. This is a necessary prerequisite for the development and implementation of preventative strategies to reduce future risks to patients.

An over-riding goal is to integrate patient safety into the routine measurement, monitoring, review, and improvement of everyday healthcare practice. ${ }^{14}$ This is critical if "across the board" change is to be achieved rather than isolated pockets of improvement. Embedding patient safety requires a particular focus on building an "open and fair" culture, tools, and expertise to support implementation of change and strong leadership engagement from clinicians and managers alike. ${ }^{12}$ It also necessitates a focus on the role of the wider healthcare policy and regulatory environment as an enabler or inhibitor of change. For example, the proposed reforms for dealing with clinical negligence in England seek to align government goals for 


\section{Box 1 National Patient Safety Agency (NPSA)}

The NPSA is a Special Health Authority established within the National Health Service with a remit to improve the safety of NHS patients through reducing the risk of harm through error.

Major responsibilities include:

- collection and analysis of information on adverse events from local NHS organisations, NHS staff and patients and carers;

- assimilation of other safety related information from a variety of existing reporting systems and other sources in the United Kingdom and abroad;

- learning of lessons, ensuring that they are fed back into practice, service organisation and delivery;

- where risks are identified, production of solutions to prevent harm, specify national goals and establish mechanisms to track progress.

The NPSA currently works with the NHS in England and Wales. ${ }^{4}$

effectively managing claims with its goals for patient safety, including greater openness with patients and better incident investigation. ${ }^{15}$

\section{PATIENT SAFETY AND THE POLICY PROCESS}

In April 2001 the Department of Health in England set out a programme of work to improve patient safety in the NHS. ${ }^{4}$ This included the establishment of the NPSA to provide leadership and the setting of national targets for safety improvement. The NPSA is not the only NHS body with responsibilities for safety. For example, a separate body is responsible for ensuring that medicines, medical devices, and equipment meet appropriate standards of safety, quality and performance. However, the NPSA is charged with the overall coordination of the NHS safety improvement effort. ${ }^{16}$

The patient safety agenda in England is gaining momentum. However, an emerging issue has been to identify the best way to work coherently across the health sector to improve systematically patient safety at a local level. Action must be taken simultaneously at different levels of the healthcare system. This includes the work of individual clinicians and teams, healthcare organisations, and within the wider policy and regulatory environment. ${ }^{17}$ In short, the success of efforts to improve patient safety is a function of how well safety is built into the fabric of the system itself. ${ }^{18}$

The design of a national patient safety strategy must therefore be firmly grounded within an understanding of the policy making process. This is the only way to ensure its effectiveness. Classical theories of the policy process describe a "top down" and essentially "rational" approach to policy making. In this model, national policy aims are formulated through a political process (with more or less inclusion of extragovernmental interests). Implementation is a largely technical process, subsequent to and distinct from the politics that characterises "policy making". ${ }^{19}$

However, many modern theorists-supported by empirical evidence from the field of policy studies_-suggest that policy and action are intertwined. To a significant extent, policy is created "bottom up". ${ }^{20}$ Those whose job it is to execute national policy (in this case, the NHS and healthcare related industries) are not merely passive recipients of national policy pronouncements. Front line staff or their host organisations are willing and, perhaps more importantly, able to mediate policy, substituting their own aims for those of government. ${ }^{21} 22$ For example, despite the existence of reporting systems, exhortative policy guidance and the like, it would appear that patient safety incidents remain significantly underreported. ${ }^{23}$

This presents a number of issues that must be addressed in developing a national strategy for patient safety. Firstly, while government and its agencies are able to establish national goals, their achievement relies upon the active engagement of a range of actors within healthcare organisations. Engagement of frontline clinical staff is particularly important. ${ }^{14}$ Secondly, compliance cannot simply be demanded by the centre but must, to a degree, be earned and negotiated. Thirdly, choices need to be made about how best to intervene. While the improvement of patient safety represents a popular ideal of health policy, in practice there is still imperfect knowledge about the choice of "levers"motivating forces for change- that will best achieve patient safety goals. ${ }^{24}$

\section{PATIENT SAFETY AND POLICY CONTEXT}

Not only must a national patient safety strategy be developed within a clear conceptual model of policy making, it must also be informed by an analysis of "policy context". The policy context incorporates factors such as culture, organisational structures, and modes of operation as well as wider political processes and ideologies that impact on the healthcare sector. This creates conditions that facilitate or hinder the achievement of policy objectives. ${ }^{25} 26$

The NHS in England is overwhelmingly publicly owned and managed. Over its lifespan of more than 50 years it has been subject to numerous programmes of fundamental reform. The latest large scale health policy initiative was set out in the NHS Plan for England and the subsequent NHS Improvement Plan. ${ }^{27}{ }^{28}$ These proposals sit within a broader policy framework of public sector reform that has been at the heart of the Blair government. ${ }^{29}$

The reform of the NHS since 1997 has been described by one of its architects as a broad range of interlinked strategies within three key domains: firstly, supporting providers of care to improve services through investments in workforce, infrastructure and developmental support; secondly, challenging NHS providers through central scrutiny, control and standard setting ("hierarchical challenge"); and lastly, challenging NHS providers through the adoption of market mechanisms and new forms of local democratic accountability ("localist challenge"). ${ }^{30}$

This new context suggests that the forces that act on the commissioners and providers of NHS care are changing and that new modus operandi for healthcare institutions will emerge. These changes can be considered from the perspectives of a "supply side" and a "demand side".

On the "supply side", market incentives within a framework of independent inspection against national quality standards are developing. A new fixed cost per case payment system (known as Payment by Results) is being implemented. $^{31}$ This is intended to promote greater contestability between providers on the basis of quality, enhanced by the entry of independent (non-NHS) providers to the healthcare market. NHS hospitals will gain independence as they increasingly transfer to "foundation trust" status and are freed from the direct control of politicians and civil servants.

On the "demand side", more than $75 \%$ of total healthcare resources have been devolved from the Department of Health to primary care trusts to enable local commissioning. The delegation of commissioning resources still further to general practice level is planned. ${ }^{32}$ Patients will have an increasing ability to choose directly their care providers, backed up by new sources of public information on comparative service 
quality. ${ }^{28}$ In addition, foundation trusts create new opportunities for patients and citizens to exercise control over NHS providers through their new position of stakeholders rather than simply that of consumers (foundation hospital governors are drawn from patients, the public, and staff).

The new context suggests that decision making over health care will transfer from the centre to local agencies, albeit bounded by national standards. Centralised performance management and accountability, the traditional means of ensuring compliance locally with national goals, is likely to feature less prominently.

\section{LEVERS FOR CHANGE}

What does this changing policy environment mean for strategy to improve patient safety? Analysis of the pluralistic US healthcare system suggests that three distinct mechanisms can be used to prompt safer actions by hospitals: professionalism, regulation, and markets. ${ }^{33}$ The new context of English health policy also suggests that these mechanisms will be significant. However, unlike pluralistic health systems with weak national or regional policy and managerial functions, the national structure of the NHS in England arguably offers a greater ability to develop a multifaceted and coherent approach which marshals resources behind public policy goals and their implementation. ${ }^{14}$ The three key levers identified as dominant within the US healthcare system may not, by themselves, be sufficient to engineer radical systemwide change.

The evolving policy environment in England offers new and different opportunities to improve safety. For example, harnessing the role of patient choice to drive and judge safety performance of providers is likely to become increasingly important. At the same time, the establishment of national standards for NHS care, of which safety forms a key component, will focus the attention of providers and commissioners on their performance in this domain. ${ }^{34}$

Nonetheless, deciding the best combination of policy levers is, to an extent, still experimental. For example, what is the right balance between external incentives such as regulation and inspection and an "intrinsic" motivation to improve such as strengthening the professional ethos of clinicians? How is the current disconnection between professional concerns for patient safety at the level of the clinician-patient interface and the formal governance of clinical quality at the organisational level most effectively addressed? ${ }^{14}$ In addition, new levers such as financial incentives are being harnessed in the interests of patient safety. Furthermore, empirical measurement of effectiveness is difficult given the close interrelationship between different interventions. ${ }^{35}$ However, it is clear that no single approach represents a complete response on its own. ${ }^{5}$

Table 1 highlights a broad range of levers for change that are being used in support of a national patient safety strategy in England, together with examples of current initiatives in these domains. The English national strategy for patient safety is evolving into a multilevel intervention using a range of different mechanisms and incentives to change behaviours among healthcare purchasers and providers. These include coherent national strategies to develop the capacity and skills of local healthcare organisations to improve safety; the use of system-wide purchasing strategies to maximise the use of

\begin{tabular}{|c|c|}
\hline Lever & Examples of current initiatives \\
\hline $\begin{array}{l}\text { Regulation and } \\
\text { inspection }\end{array}$ & $\begin{array}{l}\text { Development of national healthcare standards as the basis for inspection to be undertaken } \\
\text { by independent scrutineers, the Healthcare Commission. Patient safety has been identified } \\
\text { as a specific domain of the standards. Work is ongoing to identify criteria by which safety } \\
\text { performance should be assessed in relation to these standards to identify both poor } \\
\text { performing and high performing services. }\end{array}$ \\
\hline $\begin{array}{l}\text { Purchasing and } \\
\text { design }\end{array}$ & $\begin{array}{l}\text { Use of NHS purchasing power via a single national purchasing agency to increase safety of } \\
\text { products supplied to the NHS and the design of interventions - for example, a toolkit to help } \\
\text { hospitals review and improve their decision making about purchase of infusion devices with } \\
\text { patient safety as a key consideration. }\end{array}$ \\
\hline Market incentives & $\begin{array}{l}\text { Articulating the business case for local organisations to invest in patient safety within } \\
\text { national solutions development-for example, tools which help organisations systematically } \\
\text { to assess the cost benefit of implementing better management systems for infusion devices or } \\
\text { the introduction of alcohol gel at the hospital bedside to improve hand hygiene. In future, } \\
\text { provision of comparative safety profile information to guide consumer choices. }\end{array}$ \\
\hline $\begin{array}{l}\text { Professional ethos } \\
\text { and commitment } \\
\text { to improve }\end{array}$ & $\begin{array}{l}\text { Harnessing the commitment of professional Royal Colleges to improving patient care } \\
\text { through the appointment of patient safety champions across a range of clinical specialties. } \\
\text { Rolling out a national programme of root cause analysis training to improve skills in } \\
\text { incident investigation among frontline staff. } \\
\text { Working with higher education providers to develop safety components within professional } \\
\text { education and training. }\end{array}$ \\
\hline $\begin{array}{l}\text { Measurement and } \\
\text { system learning }\end{array}$ & $\begin{array}{l}\text { Implementation of a "national reporting and learning system" to nationally aggregate and } \\
\text { analyse patient safety incident reports in conjunction with other sources of information. } \\
\text { Feedback and publication of results. }\end{array}$ \\
\hline $\begin{array}{l}\text { Organisational } \\
\text { governance and } \\
\text { development }\end{array}$ & $\begin{array}{l}\text { Disseminating national guidance on actions to be taken by healthcare organisations to } \\
\text { support patient safety improvements. } \\
\text { Developing tools to support Boards in governance of patient safety including safety training } \\
\text { programmes - for example, dissemination of policies to reduce punitive outcomes for staff } \\
\text { following patient safety incidents and the development of tools to measure "safety culture" } \\
\text { within NHS organisations. }\end{array}$ \\
\hline NHS infrastructure & $\begin{array}{l}\text { Mobilising NHS infrastructure in the cause of patient safety by building safety } \\
\text { considerations into NHS-wide information management and technology developments } \\
\text { Influencing the estates strategy by emphasising patient safety as a parameter of good } \\
\text { design, particularly for new capital developments }\end{array}$ \\
\hline $\begin{array}{l}\text { Public and patient } \\
\text { involvement }\end{array}$ & $\begin{array}{l}\text { Ensuring that patient experience feeds into the development of national safety solutions - for } \\
\text { example, patient experience reference groups } \\
\text { Developing national guidance on staff and organisational openness with patients and } \\
\text { carers following a patient safety incident } \\
\text { In future, supporting members and public governors of foundation hospitals with } \\
\text { information about safety }\end{array}$ \\
\hline
\end{tabular}


safer healthcare products; incorporating safety into the design of healthcare facilities; and working with patients to increase their influence over safety both as consumers and as citizens holding healthcare institutions publicly to account.

\section{ROLE OF FINANCIAL INCENTIVES}

The question of developing financial incentives for safety improvement deserves special mention. As we have implied elsewhere in this paper, healthcare institutions may pursue their own corporate interests irrespective of their congruence with wider public policy goals. ${ }^{22}$ As a result, there has been a growing interest in the ways in which public policy goals can be aligned with the self-interest of organisations through the design and application of incentives and concepts of a "business case" for service quality and patient safety. ${ }^{36}$ The business case for patient safety is likely to become more compelling in the new health context in England, as providers increasingly seek to market services on the basis of quality within a tariff of prices fixed by government.

The business case approach reflects a desire to present a clear rationale for investment in patient safety improvement to mobilise commitment from organisations and healthcare professionals and investment in business change. The articulation of the business benefits of safety interventions may also help their spread among healthcare providers. However, although attractive, the business case approach has potential limitations that should be recognised and addressed if this potential is to be realised.

Firstly, the creation of "positive" incentives-for example, rewards for activities that are consistent with public policy goals-may not be sufficient to outweigh the effects of "negative" incentives (those that encourage healthcare agencies towards activities that do not support public policy goals-therefore "crowding out" these objectives-or are inimical to these goals). There is some evidence that this may be a factor in slowing uptake by hospitals of the Leapfrog Group recommendations on patient safety in the USA. ${ }^{37}$

Secondly, the impact of incentives may not always be predictable and cannot always be accurately modelled. Consequently, perverse outcomes may result. For example, it is not yet clear that sharper financial incentives for providers will lead them to raise levels of service quality, particularly where market conditions are unfavourable.

Thirdly, only governments may wish to take into account the wider societal benefits of patient safety (such as future wellbeing of patients, continued contribution to the national economy, trust in public institutions, etc), the loss of which is not easily factored into the business case of individual organisations.

Fourthly, and perhaps most significantly in terms of patient safety, some public policy goals may be effectively achieved only through concerted action across organisations of different types and with different business interests. Costs of risk mediation may fall on one organisation while the benefits accrue to another.

Thus, while the business case approach brings to bear potentially powerful new incentives for safety, a new paradigm for this approach is required. Such a paradigm must recognise the need to provide incentives at the level of the "health community" as well as the individual institution, and the need to share resulting gains between institutions, between commissioners and providers, and between clinicians and managers.

\section{IMPLICATIONS AND CONCLUSION}

Four key implications emerge for understanding and developing government initiated strategies to improve patient safety:

\section{Key messages}

- Patient safety is an integral part of the drive to improve quality in the National Health Service in England.

- The National Patient Safety Agency (NPSA) has a remit to improve the safety of NHS patients through reducing the risk of harm through error and systems failure.

- In common with many other countries, the NPSA needs to build a will for change, foster strong leadership, effectively measure safety problems and the reasons why they occur, and successfully implement interventions to address known risks.

- A range of different policy levers must operate simultaneously at all levels of the system, recognising that policies are often made "bottom up".

- The policy environment in England is changing significantly, offering new opportunities to improve safety. Market style incentives are likely to be increasingly preferred to centralised performance management and accountability as policy instruments.

- The NPSA has introduced a range of multifaceted interventions designed to embed patient safety into the fabric of health care and to achieve systemic change.

- Financial incentives and a "business case" approach to investing in patient safety are likely to become more salient in the changing policy environment in England, but also have some important limitations in their application.

- the need to understand the complexity of achieving change in health care;

- the need to recognise the limited utility of "top down" models of implementation;

- the need to analyse policy context to identify policy dynamics that can be used in support of the patient safety agenda and those that may form barriers; and

- the need to develop a multifaceted approach to mobilise and embed "across the board" change, recognising that there is an evolving evidence base about which levers in what combination are most effective.

Indeed, the impact of an overarching national agency responsible for patient safety, such as the NPSA, is itself of interest in understanding effective approaches to change. Such an agency is not a feature of all health systems, although it is perhaps intuitive that the coordination of measurement, learning, and safety interventions across a complex system will increase impact. This is an important question for evaluation in the future.

We suggest that the form of strategic analysis outlined in this paper is a vital component in the development and implementation of national patient safety strategies. The proposed World Health Organisation international alliance for patient safety has much to offer in promoting effective collaboration and learning across countries. ${ }^{38}$ Identifying and understanding effective mechanisms to translate national patient safety goals into demonstrably improved safety outcomes (that is, patient safety interventions in the domain of public policy) might usefully form an important focus for this alliance.

\section{Authors' affiliations}

R Q Lewis, Special Advisor, National Patient Safety Agency, UK and Visiting Fellow, King's Fund, London, UK 
M Fletcher, Assistant Director of Patient Safety, National Patient Safety Agency, London, UK

Conflict of interests: Richard Lewis is a paid consultant to the National Patient Safety Agency. Martin Fletcher is an employee of the National Patient Safety Agency.

\section{REFERENCES}

1 Department of Health. An organisation with a memory. London: The Stationery Office, 2000.

2 World Health Organisation Patient Safety. Rapid assessment methods for estimating hazards. Report of a WHO working group meeting, Geneva, 1719 December 2002 (available at www.who.int/patientsafety/activities/ system/en/rapid_assessment_methods.pdf).

3 Arah, OA, Klazinga NS. How safe is the safety paradigm? Qual Saf Health Care 2004;13:226-32.

4 Department of Health. Building a safer NHS for patients. London: Department of Health, 2001

5 Institute of Medicine. To err is human: building a safer health system. Washington DC: National Academy Press, 2000.

6 Leape LL, Berwick DM. Safe health care: are we up to it? BMJ 2000;320:725-6.

7 Small S, Barach P. Patient safety and health policy: a history and review. Hematol Oncol Clin North Am 2002; 16:1463-82.

8 Baker GR, Norton PG, Flintoft V, et al. The Canadian Adverse Events Study: the incidence of adverse events among hospital patients in Canada. CMAJ 2004; 170:1678-86.

9 Brennan TA, Leape LL, Laird NM, et al. Incidence of adverse events and negligence in hospitalized patients. Results of the Harvard Medical Practice Study I. N Engl J Med 1991;324:370-7.

10 Wilson RM, Runciman WB, Gibberd RW, et al. The Quality in Australian Health Care Study. Med J Aust 1995;163:458-76.

11 Vincent C, Neale G, Woloshynowych M. Adverse events in British hospitals: preliminary retrospective record review. BMJ 2001;322:517-9.

12 National Patient Safety Agency. Seven steps to patient safety. The full reference guide. February 2004 (available at: www.npsa.nhs.uk/sevensteps)

13 Runciman WB. latrogenic injury in Australia. A report by the Australian Patient Safety Foundation for the National Health Priorities and Quality Branch, Canberra, 2000

14 Leatherman S, Sutherland K. The quest for quality in the NHS. A mid-term evaluation of the 10-year quality agenda. London: The Stationery Office, 2003.

15 Department of Health. Making amends. A consultation paper setting out proposals for reforming the approach to clinical negligence in the NHS London: Department of Health, 2003.

16 Department of Health. Reconfiguring the Department of Health's arm's length bodies. London: Department of Health, 2004.
17 Berwick DM. A user's manual for the IOM's "Quality Chasm" report. Health Aff 2002;21:80-90.

18 Buchan H. Different countries, different cultures: convergent or divergent evolution for health care quality? Qual Health Care 1998;7(Suppl):62-7.

19 Barrett SM. Implementation studies: time for a revival? Personal reflections on 20 years of implementation studies. Public Admin 2004;82:249-62.

20 Barrett S, Fudge C, eds. Policy in action. London: Methuen, 1981.

21 Lipsky M. Street level bureaucracy. New York: Russell Sage, 1980

22 De Roo A, Maarse H. Understanding the central-local relationship in health care: a new approach. Int J Health Planning Manage 1990;5:15-25.

23 White $C$. Doctors mistrust systems for reporting medical mistakes. BM 2004;329:12.

24 Leatherman S, Sutherland K. Evolving quality in the new NHS: policy, process, and pragmatic considerations. Qual Health Care 1998;7(Suppl):54-61

25 Collins C, Green A, Hunter D. Health sector reform and the interpretation of policy context. Health Policy 1999;47:69-83.

26 Walt G. Implementing health care reform: a framework for discussion. In: Saltman R, Figueras R, Sakeliarides C, eds. Critical challenges for health care reform. Oxford: Oxford University Press, 1998.

27 Secretary of State for Health. The NHS plan: a plan for investment, a plan for reform. London: Department of Health, 2000.

28 Department of Health. The NHS improvement plan-putting people at the heart of public services. London: Department of Health, 2004.

29 Office of Public Sector Reform. Reforming our public services - principles into practice. London: Prime Minister's Office for Public Sector Reform, 2002.

30 Stevens S. Reform strategies for the English NHS. Health Aff 2004;23:37-44.

31 Department of Health. Reforming NHS financial flows: introducing payment by results. London: Department of Health, 2002.

32 Lewis R. Practice-led commissioning: harnessing the power of the primary care frontline. London: King's Fund, 2004 (available at: www.kingsfund.org.uk).

33 Devers KJ, Hoangmai HP, Gigi L. What is driving hospitals' patient-safety efforts? Health Aff 2004;23:103-16.

34 Department of Health. National standards, local action-health and social care standards and planning framework 2005/06-2007/08. London: Department of Health, 2004.

35 Agency for Healthcare Research and Quality. Making health care safer: a critical analysis of patient safety practices. Rockville, MD: Agency for Healthcare Research and Quality, 2001; available at: http://www.ahrq.gov/ clinic/ptsafety/summary.htm (accessed 9 July 2004).

36 Leatherman S, Berwick D, lles D, et al. The business case for quality: case studies and an analysis. Health Aff 2003;22:17-30.

37 Anon. Lack of financial incentives slows hospitals' jump to meet leapfrog safety standards. Quality Letter for Healthcare Leaders 2004;16:12-6.

38 Donaldson L. Patient safety global momentum builds. Qual Saf Health Care 2004;13:86 